\title{
“Sentido de passado" na (in)autenticidade da experiência do lugar no Bixiga
}

\author{
Thiago Rodrigues Gonçalves
}

Mestrando no Programa de Pós-Graduação em Geografia (PPGG) - Unesp (Rio Claro).E-mail: aldurin@gmail.com

Recebido em 04/2012. Aceito para publicação em 12/2012.

Versão online publicada em 01/02/2013 (http://seer.ufrgs.br/paraonde)

\begin{abstract}
Resumo: Compreender a relação dos indivíduos com seu lugar, através da mediação das manifestações culturais deve passar pela atenção não só ao componente espacial da análise geográfica, o sentido de lugar, mas, também, ao componente temporal, ao "sentido de passado", à memória constituída a partir da união entre o imaginário social e as experiências individuais no lugar, que, entendido como fenômeno, aberto e marcado por eventualidades, possibilita a compreensão da geograficidade na existência geográfica no mundo.
\end{abstract}

Palavras-chave: Autenticidade. Memória. Manifestação Cultural. Lugar. Samba.

\section{Introdução}

De que maneira se inter-relacionam o "sentido de lugar" (TUAN, 1983) e os "sentidos de passado", ancorados na memória como mediadora das relações existenciais entre indivíduos e o lugar? É possível encontrar, com base nos conceitos de "exterioridade" e "interioridade" (RELPH, 1976) pistas que contribuam para o desvelamento de relações autênticas e inautênticas dos moradores com o bairro do Bixiga?

São esses os questionamentos que levaram ao desenvolvimento do presente trabalho. Trazendo contribuições do coletivo da Geografia Humanista Cultural, especialmente aquelas produzidas após a renovação teórico-epistemológica dos anos 1970 (CORRÊA, 2010), procuramos discutir conceitos e noções que julgamos centrais na condução deste debate.

No centro da discussão, os conceitos de "exterioridade" e "interioridade" de Relph (1976), que dão conta de exprimir os variados modos de envolvimento dos indivíduos com o lugar; envolvimento que é "intersubjetivo" (TUAN, 1983), na medida em que consegue trazer para o nível essencial da consciência humana os objetos experienciados no real. Interioridade existencial e exterioridade existencial polarizam o sentido de "identidade dos" e de "identidade com os" lugares, transformando a noção de pertencimento a um lugar como condição básica da própria existência do ser (MARANDOLA JR., 2010).

Revelada a importância do conceito de iden- tidade, somos levados às reflexões de Lowenthal $(1975 ; 1977)$ que tratam de incluir na análise fenomenológica do lugar a instituição da memória (que consideramos os "sentidos de passado"). Em outras palavras, trata-se do componente temporal da análise. Memória entendida como o agente responsável pela (re)criação, (re)formulação, transformação e (re)assimilação do passado histórico como um passado mítico-moral, dando, então, novas cores ao "imaginário social” (TEVES, 2002).

É a partir da instituição, portanto, de um "imaginário social" associado ao bairro, composto por um "sentido de passado" ligado ao samba, que teremos a configuração das relações (in)autênticas dos indivíduos com o Bixiga.

Não se tratando aqui de uma discussão sobre tradição como comumente se faz, quando o assunto são manifestações culturais. Procuramos mostrar que o lugar é o resultado de inúmeras "eventualidades" e "negociações" dos indivíduos com o espaço (MASSEY, 2009). Esse conjunto de elementos sendo, então, responsável pelo aparecimento de uma geograficidade própria do Bixiga, unindo experiência (in)autêntica do lugar e o imaginário mnemônico do samba no bairro.

\section{Do lugar à geograficidade}

O lugar, concordando com o pensamento da Geografia Humanista e Cultural, é o conteúdo e o continente das relações intersubjetivas, conscientes, prenhes de significados (e significações) que exprime a ligação mais íntima entre os indivíduos e 
o espaço por onde vagam.

A relação entre indivíduos e lugar, conquanto mediada por inúmeros aspectos da realidade, será a "unidade básica" para a compreensão daquilo que é o "ser-no-espaço". A própria noção de existência (se quisermos: a realização de todas as possibilidades latentes à vida) se liga umbilicalmente a esta relação; uma vez que ao se concretizar, no cotidiano da vida ordinária, é essa relação que vai conferir materialidade à existência. Portanto, lugar é o resultado das experiências da consciência em relação à objetividade e, em igual medida, à subjetividade dos objetos da experiência.

É no lugar que vamos encontrar o combustível para uma interpretação do espaço através dos sentidos, dos saberes, dos medos, das afinidades, enfim, da subjetividade do olhar humano sobre o ambiente que lhe rodeia. Objetivando a construção do conhecimento sobre os lugares a partir das inumeráveis formas de experienciação do espaço; o escopo da vida humana naquilo que aparentemente esta carrega de mais banal, materializado no espaço imputado de sistemas de significados, logo, transformado em lugar.

A perspectiva de uma geografia da experiência, uma geografia dos fenômenos, que recoloca o Homem como meio e medida da construção do conhecimento, tem raízes nos trabalhos desenvolvidos a partir da segunda metade do século XX por um coletivo de geógrafos do mundo anglo-saxão. Buscando a aproximação entre a Geografia e as Humanidades vão trazer para o centro das preocupações uma ontologia do ser geográfico, ligado primordialmente a terra, numa relação com o telúrico do mundo, cuja expressão mais fundamental é a "geograficidade" (DARDEL, 2011) ou

\begin{abstract}
inscrições do terrestre no humano e do homem sobre a Terra, de tal modo que nem o humano nem o terrestre podem ser geograficamente pensáveis um sem o outro. [...] 0 mundo geográfico só é autenticamente acessível a partir do nível da experiência vivida, em que o terrestre e o humano se ajustam a uma medida original. (BESSE, 2011, p. 112)
\end{abstract}

Ao longo do desenvolvimento da ciência como um todo, e da geográfica em particular, muito prontamente determinaram-se quais seriam as categorias de conhecimentos e saberes considerados "legítimos" ou "verdadeiros". Em muitas situações o saber artístico compartilhado por inúmeras formas de manifestações culturais foi alijado do debate por não corresponder ao positivismo exigido e alcançado por outros conhecimentos.
No entanto, vemos hoje uma maior disposição generalizada em atravessar as barreiras impostas pelo pragmatismo positivista em direção a uma reunião de diferentes saberes na medida em que "ciência e arte encontram-se menos distante do que aparentam". (MARAN-DOLA JR.; GRATÃO, 2010, p.8).

Inscrita nessa perspectiva, adotando a geograficidade como ponto de partida para a compreensão do mundo geográfico - o espaço enquanto fenômeno -, nos preocupamos em aprofundar o debate sobre a experiência do/no lugar mediada pelas manifestações culturais. Para tanto, buscamos no bairro do Bixiga, na região central da cidade de São Paulo, a compreensão das experiências existenciais dos indivíduos no/do bairro do Bixiga através da mediação propiciada pela manifestação cultural do samba; numa associação tradicionalmente feita: falar do Bixiga é falar dos imigrantes italianos que ali se fixaram, mas também da forte presença dos africanos e de suas contribuições culturais.

Se, então, queremos compreender de que maneira interagem a experiência do lugar-Bixiga e esta específica manifestação cultural é necessário que atentemos para a constituição de tal associação, a fim de que possamos, assim, encontrar pistas da relação entre indivíduos e seu lugar.

\section{Imaginário social e o samba no Bixiga}

Segundo Nilda Teves, temos que o imaginário social se trata de

um sistema de representações cujos
sentidos traduzem um sistema de cren-
ças que legitima a ordem social em
vigor. Trata-se de uma complexa rede
de sentidos que circula, cria e recria,
instituindo/instituindo-se na luta pela
hegemonia (TEVES, 2002, p. 65)

No caso do Bixiga, o imaginário social que vai dominar as representações sobre o bairro vai ser aquele resultado das mudanças que o samba na cidade de São Paulo sofreu durante o período de que vai de 1914 a 1969, de acordo com a periodização sugerida por Dozena (2011).

Ao longo desses anos, o samba deixa de lado suas raízes rurais, dos batuques ao mesmo tempo sacros e profanos (ligados a núcleos de população negra do interior do estado de São Paulo, especialmente na cidade de Pirapora do Bom Jesus) e sua configuração em cordões carnavalescos para assumir um papel importante na condição de símbolo identitário nacional, apropriado pelo Estado e 
por ele institucionalizado. Essa institucionalização que o autor vai denominar "carnavalização do samba" (DOZENA, 2011, p. 38), trará para o samba paulista o modelo do carnaval do Rio de Janeiro, com seus desfiles contidos em momentos e espaços definidos.

Quando imaginamos o bairro do Bixiga, se o imaginamos como um "território do samba" (DOZENA, 2011, p. 25) é a imagem deste samba "carnavalizado" a que nos referimos. Cabe, portanto, desenvolver: a) De que maneira o bairro é existencialmente experienciado e b) Como se deu a construção de um "imaginário social" associando esta "expressão sambística" (DOZENA, 2011, p. 30) ao Bixiga.

\section{Lugar como fenômeno (in)autêntico}

A Geografia pode ser entendida, através de uma abordagem que a aproxime da fenomenologia, como uma geografia de lugares, desde que os lugares em si mesmos sejam compreendidos enquanto fenômenos. Edward Relph, em seu "Place and Placelessness" (1976), vai construir essa nova forma de o lugar ser pensado na Geografia, na medida em que o "lugar é a essência fundamental que permite a Relph essa edificação teórica sendo na busca do espaço existencial que ele encontra a fenomenologia e o próprio significado humanista de lugar" (MARANDOLAJR., 2010, p. 2)

Ainda segundo Marandola Jr. (2010) é fundamental na obra de Relph a influência de geógrafos seus contemporâneos dedicados à investigação sobre o lugar a partir de uma perspectiva existencial e, sobremaneira, a contribuição de filósofos da fenomenologia, em especial os trabalhos de Martin Heidegger.

A centralidade da proposta teóricometodológica de Relph (1976) está nas noções de essência e de identidade dos lugares. Suas preocupações vão conduzi-lo à percepção do lugar, livre das amarras positivistas, como o resultado da experiência subjetiva dos indivíduos na relação com o lugar. Como já ressaltado, a essência do lugar em Relph está na noção de espaço existencial: a condição de intimidade profunda, primeva, do homem com o espaço, na medida em que, apoiando-se em Heidegger, Relph vai afirmar que "pertencer [...] não é pertencer a, mas [...] que pertencer é ser" (MARANDOLAJR., 2010, p.5).

Logo, pode-se afirmar que a partir da essência existencial e relacional do envolvimento entre homem-lugar, sustenta-se a constituição da "identidade dos lugares" em associação fenomênica com a "identidade com os lugares". Estar aí, é ao mesmo tempo condição para que o indivíduo seja plenamente e para que ao experienciar o lugar, numa atitude consciente, confira ao lugar a parcela de sentidos e significados, atividades e configuração física (MARANDOLA JR., 2010, p. 3) que, em realidade, é a epítome da geograficidade.

A partir daí, do desenvolvimento da noção de identidade dos/com os lugares na perspectiva fenomenológica e da reflexão sobre a essência da experiência dos lugares, Relph (1976) diferencia as "possibilidades de envolvimento" do ser com o lugar entre os conceitos de interioridade (insideness) e exterioridade (outsideness). Variando entre a experiência mais direta possível do/com o lugar ("interioridade existencial") e o mínimo experiencial indireto, "exterioridade existencial", as possibilidades de envolvimento serão responsáveis por fazer-nos compreender que a relação com os lugares pode ser diversa e variada. Da mesma forma é possível compreender que a identidade dos lugares construída nessa relação é ao mesmo tempo responsável pela diferenciação dos lugares e pela criação de uma unidade interna, já que individualmente há uma identificação com os lugares (MARANDOLA JR., 2010, p. 6).

Interioridade e exterioridade na identidade dos/com os lugares será uma via de entendimento da realidade tomada como existência; oscilando entre uma existência fundada na autenticidade e/ou na inautenticidade da atitude responsável dos indivíduos com relação à própria existência e, ao mesmo tempo, do envolvimento inconsciente em seu mundo imediato (MARANDOLA JR., 2010, p.7).

A busca pela (in)autenticidade na relação existencial dos homens com os seus lugares passa pela compreensão de aspectos associados à constituição do "imaginário social" relativo aos lugares e, como nos mostra David Lowenthal (1977), também relativo a uma população que cria sua unidade interna, sua parcela de (in)autenticidade, a partir destes referenciais.

\section{Do "sentido de passado" ao "sentido de lugar"}

Nos trabalhos de Lowenthal, a perspectiva existencial da experiência do espaço será composta por diversos aspectos pertencentes à realidade. Dentre esses aspectos, em muitos de seus trabalhos, o autor dedicará tempo e esforços para desvelar o que entendemos como "sentido de passado" na construção de um imaginário social que dirigirá as formas de relação (ou de envolvimento) dos indivíduos com o espaço que os rodeia. Esse "sentido de passado" pode ser entendido como um senti- 
mento de nostalgia de um passado distinto do presente (LOWENTHAL, 1977). Em muitos casos, um passado valorizado como melhor ou mais virtuoso, na medida em que estão lá (não no aqui, no presente) as fundações de uma sociedade menos doente, menos problemática.

Lowenthal vai utilizar as comemorações do bicentenário da declaração de independência dos Estados Unidos da América para esmiuçar a relação construída entre os indivíduos norteamericanos de 1976 com aquele conjunto de fatos associados à luta pela independência em 1776. Ao longo de sua análise cuidadosa, Lowenthal vai identificar três modos distintos, ainda que complementares, de revisão, reaproximação e renovação do passado naquele momento de comemorações pelo qual passava o conjunto da sociedade norteamericana: a) Afirmação simbólica, celebrando o passado com palavras e slogans; b) Reprodução e preservação de objetos tangíveis, na forma de construções e outros artefatos; e, por fim, c) Ações diretas na paisagem, com a reencenação de eventos passados (LOWENTHAL, 1977, p. 258).

Em todos esses modos de culto ao passado temos um "sentido de história" (LOWENTHAL, 1977, p. 257) que permeia as comemorações e, de maneira, geral, toda a relação dos norteamericanos com seu passado. Um passado que não prioriza os fatos históricos mais do que a mitificação de eventos que podem vir a ser significativos para as atuais audiências. Não há interesse na compreensão, ou mesmo, no entendimento de referenciais históricos mais antigos do que a Revolução Americana de 1776 nem a intenção de unir esse evento a um contexto mais alargado, dando-lhe novas e outras perspectivas (LOWENTHAL, 1977).

De que forma, portanto, o "sentido de passado" (essa relação literalmente construída dos indivíduos com sua percepção de um passado histórico através da mitificação ou moralização desse passado) pode ser um aspecto na compreensão do nascimento do envolvimento existencial autêntico (ou inautêntico) dos indivíduos com seus lugares? É possível que haja uma correlação entre passado percebido ("sentido de passado") e a criação de "sentido de lugar" (TUAN, 1983)?

Entendemos que a investigação do "sentido de passado" associado à noção de "sentido de lugar", através das variadas formas de experiência existencial dos indivíduos no espaço, possa contribuir para a compreensão dos questionamentos apresentados. Ao mesmo tempo em que incrementa nossa capacidade de compreensão holística do lugar, almejando a construção de uma geografia da experiência.

\section{A memória como componente temporal da aná- lise geográfica}

Nesse sentido, consideramos que seja enriquecedor uma maior atenção ao papel da memória quando buscamos a compreensão dos envolvimentos (in)autênticos do homem com seu lugar. Isto porque, conforme aponta Lowenthal (1975, p. 27, tradução nossa): "O passado tangível se altera principalmente para estar em conformidade com a memória". Em outras palavras, cabe adicionar a dimensão temporal às descrições e às análises geográficas do espaço; mas cuidando para que, ao longo da tentativa, saibamos, por assim dizer, separar o joio do trigo, uma vez que "acima de tudo, a memória transforma o passado que conhecemos naquilo que achamos que ele deveria ter sido" (LOWENTHAL, 1975, p. 28, tradução nossa).

A percepção do "passado mítico ou moral" (LOWENTHAL, 1977), aquele que é alterado pela nossa memória individual, ou que é reescrito à maneira mais adequada para e pelo imaginário social, não tem, na maior parte das vezes, a preocupação com o rigor dos fatos. Ainda que esteja baseado em eventos historicamente localizados, muito do que é percebido como valioso, importante ou basilar no antes é dessa forma elegido por questões mais subjetivas (individual ou coletivamente formuladas). E, no entanto, defendemos aqui: mesmo essa percepção pode contribuir para a destilação dos "entretantos" na relação entre indivíduos e espaço.

Atentar para o componente temporal na constituição das relações de envolvimento com o lugar, portanto, exige (se não, mesmo, prescinde) de uma "escavação" do "reino do passado" (LOWENTHAL, 1977, p. 254) para que desvelemos até que ponto o que se afirma como fato histórico não sinaliza ou significa uma alteração do passado tal como foi em função de demandas (de entendimento, de representação, de identidade, de significação, etc.) modernas.

No caso do bairro do Bixiga, em São Paulo, como já exposto, essa possível relação (in)autêntica com o lugar, vai se dar através também (mas não somente), da mediação criada pela presença marcante dos lugares associad os ao samba no bairro, que têm, hoje, relevante papel na manutenção de uma unidade interna entre indivíduos e aquele lugar.

As pessoas que caminham pelas ruas e vilas e ladeiras e escadarias do Bixiga entendem muito mais de suas geografias do que os geógrafos em suas academias poderiam sonhar. Por quais ruas passar ou não se estão com pressa, onde sentar 
para acompanhar o dia que termina ou começa, o melhor horário para chegar à quadra do Vai-Vai em dia de ensaio da escola, o ponto de ônibus mais perto, a melhor padaria, a cantina para não turistas, que serve o melhor fettuccine, que tem a melhor carta de vinhos, enfim. E isto, claro, não é privilégio dos moradores do Bixiga. Mesmo os geógrafos, esses perscrutadores das relações do Homem com a Terra, conhecem os melhores caminhos, têm seus cantos preferidos e odiados nesse mundo.

Esse conhecimento, que é geográfico, mas não necessariamente é científico, existe em consonância com um sem-número de outras influências e variáveis. Aproximamos-nos nesse artigo do coletivo de pesquisadores sobre o lugar (os geógrafos, especialmente) que atenta para um desses aspectos do real que moldam (ou compõem) a experiência humana do espaço: o componente temporal, representado pela instituição da memória, que tudo modifica, interfere e reconstrói, segundo as exigências de imensas e opressivas determinações históricas, mas, também, e em igual importância, segundo as demandas individuais mais corriqueiras, mundanas - humanas.

A memória é resultado e resultante da reconstrução e reinterpretação do passado. Passado que é histórico, na medida em que está organizado segundo eventos numa flecha do tempo cronológico, que é geográfico, já que a própria história é o tempo especializado, mas que pode (e eis a chave da questão) ser de tal forma reescrito e reinterpretado e remendado que sua componente histórica dá espaço a um conjunto mítico-moral que será a matéria-prima da memória - e, como consequência, dizemos com Lowenthal (1977), matériaprima da percepção, da experiência e da significação do lugar.

\section{Tradição e memória: a partir do desenvolvi- mento da Geografia Cultural}

A dimensão temporal que gostaríamos de ver incluída nas preocupações geográficas sobre o lugar, isto é, a memória, em sentido algum advoga pela associação com a ideia de tradição cultural tal como ela é percebida em textos científicos e, mesmo, no senso comum. Ainda que as inúmeras lutas pelas preservação de manifestações culturais, as mais diversas, associem memória e tradição, as duas noções não precisam necessariamente caminhar juntas.

Numa preocupação que acompanha o desenvolvimento dos trabalhos da Geografia Cultural, especialmente após os anos 1970, quando a corrente de pensamento passa por uma profunda revisão e renovação conceitual e epistemológica (CORRÊA, 2010; CLAVAL, 1999), o conceito de cultura utilizado deixou de ser aquele associado às definições propostas pelo coletivo de antropólogos baseados em Berkeley, na Universidade da Califórnia, nos primeiros anos do século XX.

A partir dos trabalhos dos antropólogos norte-americanos Albert Kroeber e Leslie White, o conceito de cultura ganhou a Antropologia sob a condição de ser uma "entidade superorgânica", "misteriosa", que relegaria aos indivíduos (e ao contexto histórico em que se inserem) um papel secundário, como meio para a realização de planos e desígnios além de seu alcance (DUNCAN, 2011; CORRÊA, 1989). Noutras palavras, é dizer que a cultura seria uma determinação universal (intocável, inatingível) do "caráter dos povos" (DUNCAN, 2011, p. 65), estando livre de interferências, "seria, então um processo sui generis" (DUNCAN, 2011, p. 69).

O geógrafo Carl Sauer, que funda a Geografia Cultural durante as décadas de 1920 e 1930, foi amigo de Kroeber e White (DUNCAN, 2011) e, através deles, incorporou em sua nascente proposta de renovação metodológica para a Geografia a noção de cultura como uma entidade superorgânica (CORRÊA, 1989). A partir daí, os estudos filiados a essa escola do pensamento geográfico estiveram presos à visão de cultura da Antropologia de Berkeley e, como consequência, muito do que hoje compreendemos como relevante na constituição dos fenômenos culturais foi deixado de lado. Não é, senão, apenas na década de 1970 que novas formas de aproximação com os diversos objetos de estudo da Geografia Cultural serão aceitas e postas em prática (CORRÊA, 2001).

Tradição, pela própria semântica do vocábulo, assume uma perspectiva de imobilidade associada às manifestações culturais. Não se espera que o que seja tradicional mude; ainda que a possibilidade de avanço a partir da relação dos indivíduos com o meio exista; daí derivam, portanto, as iniciativas de preservação e proteção de tais manifestações, como atestam as definições contidas no texto final da Convenção para a Proteção do Patrimônio Intangível, encontrado no site da UNESCO dedicada ao Patrimônio Cultural Imaterial ou Patrimônio Cultural Intangível:

A "herança cultural intangível" significam as práticas, representações, expressões, conhecimento, habilidades - bem como os instrumentos, objetos, artefatos e espaços culturais associados a eles - que comunidades, grupos e, em alguns casos, indivíduos reco- 
nhecem como parte de sua herança cultural. Essa herança cultural intangível, transmitida de geração em geração, é constantemente recriada por comunidades e grupos em resposta a seus ambientes, sua interações com a natureza e sua história e lhes confere um sentido de identidade e continuidade, desse modo promovendo respeito pela diversidade cultural e criatividade humana. (UNESCO, 2003, p. 2 - grifo nosso, tradução nossa)

Memória, como exposto, se trata do passado recriado, reescrito, reinventado como um todo em alguns casos pela ação do imaginário social ou como atitude inconsciente individual. Esse processo, conquanto, sim, possa ser orientado no sentido de alterar registros históricos em favor deste ou daquele grupos é processo inconsciente ao nível do indivíduo, que pode chegar a esferas para além deste, mas nasce fundamentalmente do relacionamento do indivíduo com o passado.

\section{O lugar e a eventualidade: "Se nada é fixo, que é o aqui?"}

Nesse sentido, é importante notar que Doreen Massey, em seu "Pelo espaço" (2009) vai nos ensinar que os lugares estão sujeitos a uma "eventualidade" (MASSEY, 2009, p. 203). E que esta eventualidade não nos permite pensar o lugar como um ponto, cartesianamente fixo, imutável, cenário de determinações externas a si (culturais, ambientais, técnicas, econômicas, o que seja) uma vez que

o que é especial a respeito do lugar não é algum romantismo de uma identidade coletiva preconcebida ou de uma eternidade das montanhas. Ao contrário, o que é especial sobre o lugar é, precisamente, esse acabar juntos, o inevitável desafio de negociar um aqui-e-agora (ele mesmo extraído de uma história e de uma geografia de "entãos" e "lás"), e a negociação do que deve acontecer dentro e entre ambos, o humanos e o não humano. (MASSEY, 2009, p. 203 grifo nosso)
A Geografia Cultural saueriana precisava considerar que no interior do que chamavam "área cultural" ou "paisagem cultural" deveria existir uma homogeneidade cultural que matinha aquela área uniforme, quase estanque (CORRÊA, 1989). O que Massey vai nos ensinar é que o lugar "não [é] intrinsecamente coerente" (MASSEY, 200, p. 203), na medida em que

Isso é a eventualidade do lugar, em parte, no simples sentido de reunir o que previamente não estava relacionado, uma constelação de processos, em vez de uma coisa. Este é o lugar enquanto aberto e enquanto internamente múltiplo, não capturável como um recorte através do tempo no sentido de um corte essencial. (MASSEY, 2009, p. 203)

Se a memória é uma possibilidade de adicionar o componente temporal à análise geográfica do lugar, e se ela é responsável pela recriação de um passado histórico na forma de um passado mítico-moral, é lícito imaginar que, seja no Bixiga, seja em qualquer outra cidade, a (in)autenticidade da experiência do lugar fica indelevelmente associada à memória que surge da minha relação íntima e consciente com a terra, da minha geograficidade.

\section{Conclusão}

É importante que novas preocupações permeiem a Geografia, multiplicando o alcance do esforço empreendido na busca pela decifração da relação Homem-Espaço. É nesse sentido que nos preocupamos em contribuir para o debate, trazendo olhares renovados que tratam da aproximação com o lugar enquanto categoria de análise.

O lugar, quando compreendido como fenômeno (RELPH, 1976; MARANDOLA JR., 2010), guarda em si um potencial inestimável para a ciência geográfica, se esta pretende apreciar as nuances da relação fenomênica entre indivíduo e lugar. Não há, por assim dizer, limites ou fronteiras num conhecimento que existe no seio do ser, da mesma forma que não existem limites para as "possibilidades de envolvi- 
mento" (RELPH, 1976) do ser com o espaço que lhe circunda (compõe, atravessa, distingue e desafia).

A música, tanto quanto as outras formas de expressão artística, carrega em si mesma um componente que é, em essência, geográfico. Os temas, as técnicas musicais, o desenvolvimento, isto é, o surgimento e desaparecimento de gêneros e estilos musicais não acontecem (se realizam) se não ancorados a um espaço. Os gêneros musicais associados ao folclore, às tradições, à memória de um povo têm relação direta e explícita com o lugar que exaltam, hostilizam, lembram, amam ou odeiam.

O samba no Brasil, em suas várias "encarnações" não foge a esta regra, uma vez que é o resultado das infinitas "negociações" e "eventualidades" (MASSEY, 2009) contidas nos lugares associados ao seu nascimento, à sua perpetuação, à sua prática festiva e/ou cotidiana. Pelos quatro cantos do Brasil, a influência africana, trazida por milhões de escravos negros, associada às exigências de um "imaginário social" (TEVES, 2002) cioso da preservação da herança colonial europeia fez surgir um gênero e um ritmo singulares. Nos descaminhos histórico-geográficos, parte dessa mistura achou de firmar uma de suas expressões no bairro operário do Bixiga, no coração da cidade de São Paulo. E é nessa relação, entre um passado que é, ao mesmo tempo, "histórico e mítico-moral" (LOWENTHAL, 1977), que vamos procurar compreender a construção de uma relação "(in)autêntica" (RELPH, 1976) entre as pessoas (e suas existências de experiências) e o lugar, repleto de sentidos e significados.

Ao buscar a influência do "sentido de passado" nesta relação, nos parece indispensável atentar para a instituição da memória como agente na transmutação de referenciais de passado que serão, ao fim e ao cabo, insumo para a constituição de uma geograficidade ali, entrelaçada, entre a Avenida 9 de Julho e a Rua 13 de Maio.

\section{Referências}

BESSE, Jean-Marc. Geografia e Existência a partir da obra de Eric Dardel. In: DARDEL, E. O Homem e a Terra: natureza da realidade geográfica. São Paulo: Perspectiva, 2011, p. 111-139.
CLAVAL, Paul. A Geografia e a percepção do espaço. Rio de Janeiro: Revista Brasileira de Geografia, ano 45, n. 2, abr._jun., p. 243-256, 1983.

CORRÊA, Roberto L. Carl Sauer e a Escola de Berkeley: uma apreciação. In: ROSENDAHL, Z.; CORRÊA, R. L. (orgs.). Matrizes da geografia cultural. Rio de Janeiro: EdUERJ, 2001, p. 9-33.

Carl Sauer e a Geografia Cultural. Rio de Janeiro: Revista Brasileira de Geografia, ano 51, n. 1, p. 113-122, 1989.

Temas e caminhos da geografia cultural: uma breve reflexão. In: ROSENDAHL, Z.; CORREAA, R. L. (orgs.). Temas e caminhos da geografia cultural. Rio de Janeiro: EdUERJ, 2010, p. 11-35.

DARDEL, Eric. 0 Homem e a Terra: natureza da realidade geográfica. São Paulo: Perspectiva, 2011.108p.

DOZENA, Alessandro. A geografia do samba na cidade de São Paulo. São Paulo: Fundação PoliSaber, 2011. 264 p.

DUNCAN, James S. O supraorgânico na geografia cultural americana. In: CORREAA, R. L.; ROSENDAHL, Z. (orgs.). Introdução à geografia cultural. Rio de Janeiro: EdUERJ, 2011, p.63-102.

LOWENTHAL, David. Past time, present place: landscape and memory. Geographical Review, v. 65, n. 1, p. 1-36, 1975.

The bicentennial landscape: a mirror held up the past. Geographical Review, v. 67, n. 3, p. 253-267, 1977.

MARANDOLA JR. Eduardo; GRATÃO, Lúcia H. B. "Geograficidade, Poética e Imaginação" In: MARANDOLA JR., E.; GRATÃO, L. H. B. (orgs.). Geografia e Literatura: ensaios sobre geograficidade, poética e imaginação. Londrina: EDUEL, 2010, p. 7-15.

MARANDOLA JR., Eduardo. Identidade e autenticidade dos lugares dos lugares: o pensamento de Heidegger em Place and Placelessness, de Edward Relph. In: XVI Encontro Nacional de Geógrafos - ENG, 16, 2010, Porto Alegre. Anais... Porto Alegre: AGB, 2010.

MASSEY, Doreen B. Pelo espaço: uma nova política da espacialidade. Rio de Janeiro: Bertrand Brasil, 2009. $314 \mathrm{p}$.

RELPH, Edward. Place and placelessness. London: Pion, 1976.156p.

TEVES, Nilda. Imaginário social, identidade e memória. In: FERREIRA, L. M. A.; ORRICO, E. G. D. (orgs.). Linguagem, identidade e memória social: novas fronteiras, novas articulações. Rio de Janeiro: DP\&A, 2002, p. 5368. 
TUAN, Yi-Fu. Espaço e lugar: a perspectiva da expe-

riência. São Paulo: Difel,1983, 249p.

UNITED NATIONS EDUCATIONAL, SCIENTIFIC AND

CULTURAL ORGANIZATION. Text of the Convention for

the Safeguarding of Intangible Cultural Heritage,

2003, Paris, 15p. Disponível em: <http://portal.unesco

.org/en/ev.php-URL_ID=17716\&URL_DO=DO_TOPIC

\&URL_SECTION=201.html >. Acesso em 24 março 2012.

\title{
"Sense of the Past" in the (In)Authenticity in the Experience of the Place in Bixiga
}

\begin{abstract}
To comprehend the relationship between individuals and their place through the mediation of cultural manifestations must pay attention not only to the spatial component of geographical analysis, the sense of place, but also to the temporal component, the "sense of the past", the memory formed from the union between the social imaginary and individual experiences in the place, which, understood as a phenomenon, open and marked by eventualities, allows for the understanding of the geographicity in the geographical existence in the world.

Keywords: Authenticity. Memory. Cultural Manifestation. Place. Samba.
\end{abstract}

\section{El "Sentido de Pasado" en la (In)Autenticidad de la Experiencia del Lugar en el Bixiga}

Resumen: Comprender la relación entre los individuos y su lugar, a través de la mediación de las manifestaciones culturales debe prestar atención no sólo a el componente espacial de análisis geográfico, el sentido de lugar, sino también a el componente temporal, el "sentido del pasado", a la memoria que consiste de la unión entre el imaginario social y las experiencias individuales en el lugar, que, entendido como un fenómeno, abierto, marcado por la eventualidad permite la comprensión de la geograficidad de la presencia geográfica en el mundo.

Palabras-clave: Autenticidad. Memoria. Manifestación Cultural. Lugar. Samba. 